\title{
Addition of a channel for XCO observations to a portable FTIR spectrometer for greenhouse gas measurements
}

\author{
Frank Hase $^{1}$, Matthias Frey ${ }^{1}$, Matthäus Kiel ${ }^{1}$, Thomas Blumenstock ${ }^{1}$, Roland Harig ${ }^{2}$, Axel Keens ${ }^{2}$, and \\ Johannes Orphal ${ }^{1}$ \\ ${ }^{1}$ Karlsruhe Institute of Technology (KIT), Institute for Meteorology and Climate Research (IMK-ASF), Karlsruhe, Germany \\ ${ }^{2}$ Bruker Optik GmbH, Ettlingen, Germany \\ Correspondence to: Frank Hase (frank.hase@kit.edu)
}

Received: 22 December 2015 - Published in Atmos. Meas. Tech. Discuss.: 18 January 2016

Revised: 28 April 2016 - Accepted: 12 May 2016 - Published: 25 May 2016

\begin{abstract}
The portable FTIR (Fourier transform infrared) spectrometer EM27/SUN, dedicated to the precise and accurate observation of column-averaged abundances of methane and carbon dioxide, has been equipped with a second detector channel, which allows the detection of additional species, especially carbon monoxide. This allows an improved characterisation of observed carbon dioxide enhancements and makes the extended spectrometer especially suitable as a validation tool of ESA's Sentinel 5 Precursor mission, as it now covers the same spectral region as used by the infrared channel of the TROPOMI (TROPOspheric Monitoring Instrument) sensor. The extension presented here does not rely on a dichroic, but instead a fraction of the solar beam is decoupled near the aperture stop of the spectrometer using a small plane mirror. This approach allows maintaining the camera-controlled solar tracker set-up, which is referenced to the field stop in front of the primary detector. Moreover, the upgrade of existing instruments can be performed without alterating the optical set-up of the primary channel and resulting changes of the instrumental characteristics of the original instrument.
\end{abstract}

\section{Introduction}

The ground-based solar absorption FTIR (Fourier transform infrared) technique is capable of providing highly reliable measurements of column-averaged $\mathrm{CO}_{2}$ and $\mathrm{CH}_{4}$ abundances. The TCCON (Total Carbon Column Observing Network; Wunch et al., 2011) is one of the established references for the validation of greenhouse gases measuring space sen- sors (Reuter et al., 2011; Wunch et al., 2011; Butz et al., 2011; Heymann et al., 2015; Inoue et al., 2016) and has also been used for e.g. model studies of greenhouse gases sources (Messerschmidt et al., 2013) and observation of local sources (Lindenmaier et al., 2014). Recently, several investigators demonstrated that portable low-resolution FTIR spectrometers still allow surprisingly precise and accurate measurements of column-averaged greenhouse gas abundances (Petri et al., 2012; Gisi et al., 2012; Frey et al., 2015). Such devices are a promising supplement to the TCCON, for performing measurements at remote sites, for mobile applications (Klappenbach et al., 2015), and for observations of dedicated sources and sinks on regional and smaller scales (Hase et al., 2015).

In this work, we describe an instrumental extension of the system introduced by Gisi et al. (2012), comprised of a portable FTIR spectrometer based on a pendulum interferometer design and a camera-controlled solar tracker for ensuring proper alignment of the line of sight on the solar disc centre (Gisi et al., 2011). This spectrometer is available today as a standard device from the Bruker Optics company in Ettlingen, Germany, under the model name EM27/SUN and is used by many working groups. The observing strategy follows the same approach demonstrated by the TCCON: the near-infrared spectral bands of the greenhouse gases under study are co-recorded with the $1.27 \mu \mathrm{m}$ band of molecular oxygen. Thereby, the column-averaged dry-air mole fractions of a target species can be derived from the ratio of the target species column divided by the molecular oxygen column. This process takes advantage of our accurate knowledge of the dry-air mole fraction of molecular oxygen and 
helps to reduce various error sources (Wunch et al., 2011). In addition, the TCCON uses DC-coupled interferograms for improving the precision of the measurements and for quality flagging (Keppel-Aleks et al., 2007), which is also used for the portable spectrometers. The main difference is that the spectral resolution of the portable spectrometer is much lower: it provides double-sided interferograms with a maximum optical path difference (OPDmax) of $1.8 \mathrm{~cm}$, while the TCCON applies $45 \mathrm{~cm}$ or higher OPDmax. An instructive example of application is provided by Hase et al. (2015), where a set of five EM27/SUN spectrometers has been used for detecting the carbon-dioxide-enriched plume generated by the major city Berlin. The current EM27/SUN spectrometer offers a spectral coverage of about $5500-11000 \mathrm{~cm}^{-1}$, slightly broader than the $6000-11000 \mathrm{~cm}^{-1}$ coverage used for the prototype described by Gisi et al. (2012). This still conservative choice has been made to avoid any compromise of measurement accuracy of the primary target species $\mathrm{XCO}_{2}$ and $\mathrm{XCH}_{4}$. Nevertheless, it would be highly desirable to add the capability of observing XCO, which is a valuable tool for the characterisation of sources connected to observed $\mathrm{XCO}_{2}$ enhancements (Wunch et al., 2009). Moreover, an extension of the spectral coverage of the current EM27/SUN including the $2.3 \mu \mathrm{m}$ region used by TROPOMI (TROPOspheric Monitoring Instrument) for the observation of carbon monoxide and methane would qualify the mobile spectrometer as a validation instrument for the Sentinel 5 Precursor mission. Here, we introduce an enhancement of the EM27/SUN by adding the capability of measuring XCO. In Sect. 2 we provide a summary of the basic design considerations, in Sect. 3 we describe the practical implementation of the extension, in Sect. 4 we present the characteristics of lamp and atmospheric solar spectra recorded with the dual-channel prototype, and in Sect. 5 we demonstrate the performance of the novel set-up based on retrievals of atmospheric observations. Section 6 provides a summary of this study and an outlook towards planned future activities.

\section{Design considerations for the XCO extension}

The most straightforward approach for an XCO extension is obviously the replacement of the standard indium gallium arsenide (InGaAs) diode covering $5500-11000 \mathrm{~cm}^{-1}$ by a detector element offering extended spectral coverage. However, as the FTIR technique reconstructs the irradiated spectrum by performing a Fourier transformation of the measured interferogram, it is susceptible to characteristic interfering influences which degrade the recorded interferogram. Periodic sampling errors, non-linear detector response, or radiation which is reflected back into the interferometer and modulated twice before detection (double passing) can all generate parasitic signals in the spectral domain. If the spectrum is confined to a sufficiently narrow region, the spectral perturbations can be detected (and corrected if necessary) by the characteristic out-of-band artefacts they create, or they can be tolerated if the parasitic spectral signal does not overlap with the real spectral signal. Increasing the spectral bandwidth not only significantly increases the noise level of the spectrum but is - more seriously - possibly harmful as well due to an insufficient level of control of the interfering influences mentioned above. The application of an extended InGaAs diode has been investigated (Hedelius et al., 2016) but resulted in a significant dependence of $\mathrm{XCO}_{2}$ and $\mathrm{XCH}_{4}$ on the overall signal level, probably due to a non-linear detector response. This characteristic, which damages the reliability of the EM27/SUN primary data products, is highly undesirable and is not observed with the standard detector element.

An alternative approach is the use of an additional detector element for widening the covered spectral region. This avoids the aforementioned problems but requires (1) the use of a sandwich detector element, (2) alternating observations with different detectors, or (3) the distribution of the optical beam for feeding two separated detector elements at a time.

A sandwich detector comprised of two sensors with different spectral coverage is a delicate item of limited availability and considerably higher cost than a pair of separate detectors. Moreover, the increased number of stacked substrate interfaces promotes the occurrence of optical resonances, which generate undulations in the spectral domain ("channelling"), a highly undesirable feature from the viewpoint of quantitative spectral analysis of crowded spectral scenes as provided by the atmosphere.

The second option of alternating observations is accompanied by the drawback that species recorded in the two channels are not recorded simultaneously; it reduces the duty cycle of the measurement; and it requires an additional moving optical element in the detector branch of the spectrometer, which gives rise to further risks, such as variable misalignment or complete failure of the unit.

Therefore, the third approach seems most promising. This approach has also been realised in the TCCON spectrometer operated by KIT near Karlsruhe: here, a dichroic allows simultaneous observation of the shortwave part of the spectral region (covering $\mathrm{O}_{2}, \mathrm{CO}_{2}$, and $\mathrm{CH}_{4}$ ) together with either the longwave part (covering $\mathrm{HF}, \mathrm{N}_{2} \mathrm{O}$, and $\mathrm{CO}$ ) for achieving the same spectral coverage as the standard extended InGaAs diode used by other TCCON sites or a spectral section in the mid-infrared spectral region as observed by spectrometers of the NDACC (Network for the Detection of Atmospheric Composition Change). The set-up uses the same InGaAs detector as the EM27/SUN for the shortwave and a liquidnitrogen-cooled indium antimonide (InSb) detector for the longwave part of the spectrum. Further details and results achieved with this set-up are provided by Kiel et al. (2016a, b). The remaining drawback of the approach is that a specific dichroic is required, which complicates the alignment of the detector branch and generates undulations of the spectral sensitivity. The presence of undulations requires special attention in the processing of the spectra (Kiel et al., 2016a). In the case of the Karlsruhe high-resolution set-up, any loss of 


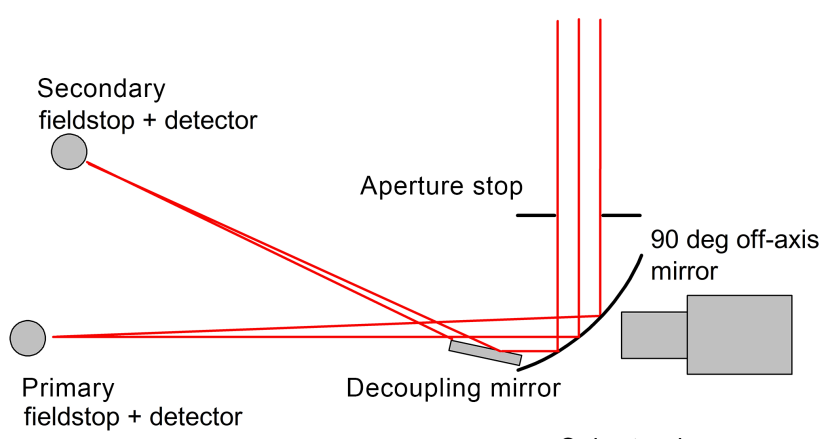

Solar tracker camera

Figure 1. Schematic drawing of the detector branch of the extended EM27/SUN. The camera is located above the drawing plane and images the primary field stop. For clarity, the camera position has been shifted to the right in the drawing; it actually is located above the off-axis mirror.

the interferometric etendue (product of supported beam area and covered solid angle) permitted by the hardware configuration is undesirable in the InSb branch, because the NDACC type of measurements is performed with narrow optical filters at very high spectral resolution. Therefore, the choice of using a dichroic of good efficiency seems justified.

From the viewpoint of the EM27/SUN extension, the situation differs, as the interferometric etendue is deliberately limited by an adjustable iris acting as an aperture stop. The detector uses only a small fraction of the etendue supported by the interferometer and solar tracker hardware, and a loss of signal can easily be compensated by a slight adjustment of the iris aperture. Therefore, in this case a wave front division seems the most appropriate approach. If finally this wave front division is executed near the aperture stop of the interferometer (defined by an adjustable iris), the characteristics of the existing detector branch remain unimpaired, and with proper geometrical arrangement of the extension set-up even the functionality of the camera-controlled solar tracker, which references the solar image to the position of the field stop aperture in front of the existing detector, is maintained.

\section{Technical set-up of the prototype}

Figure 1 shows a schematic sketch of the partial beam decoupling and the longwave detector branch. Behind the adjustable iris aperture that defines the aperture stop of the system, an off-axis paraboloidal mirror is located, which offers $127 \mathrm{~mm}$ effective focal length and generates a solar image on the field stop in front of the existing detector element. Physically, the field stop is realised by a circular hole of $0.60 \mathrm{~mm}$ diameter in a thin disc of stainless steel. For partial decoupling of the beam, a plane mirror of $10 \times 20 \mathrm{~mm}^{2}$ size has been added. This mirror is located directly behind the offaxis paraboloid and accepts about $40 \%$ of the incoming converging beam. The deflection angle between the residual parent and reflected partial beam amounts to about $25^{\circ}$, and the
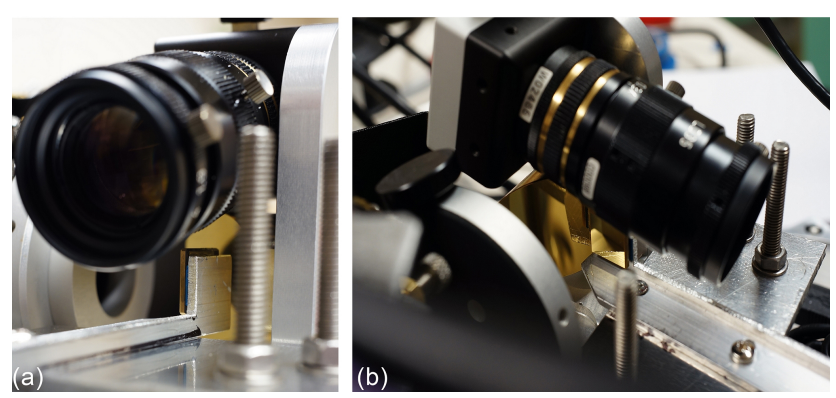

Figure 2. Close-up of the plane mirror used for decoupling of the secondary beam. (a) (left side) shows the support arm which carries the mirror. The mirror itself is seen from the back. On the left, parts of the circular mounting of the adjustable iris are seen. Behind the contours of the plane mirror, the larger off-axis paraboloid is located. Above the mirror, the camera used for the camera-controlled solar tracker is located. (b) (right side) offers a different perspective: below the camera, the front side of the plane mirror is seen. The frame of the iris is seen from the back.

deviation is chosen along the horizontal, so that the second detector element can be mounted next to the original detector.

The solar image is formed on a secondary aperture stop $(0.80 \mathrm{~mm}$ diameter $)$ in front of the additional detector element. The detector element used is a windowless extended InGaAs diode (cut off $4000 \mathrm{~cm}^{-1}$ ) offering a $1 \mathrm{~mm}^{2}$ sensitive area. In a gap between the secondary field stop and the diode a wedged Germanium long-pass filter is mounted, which shields the extended InGaAs diode from the spectral section already covered by the primary detector.

Figures 2-4 show close-up photographs of the dualdetector prototype. Figure 2 shows the small plane mirror just in front of the off-axis paraboloid. The mirror is glued with a two-component epoxy resin adhesive to its aluminium support. The bonding layer has been chosen to be thick and flexible enough to avoid deformation of the glass mirror due to temperature changes. The support structure allows fine adjustment of the direction of the beam reflected towards the secondary field stop. Figure 3 shows the image of an artificial source on the primary and secondary field stop. Figure 4 shows the detectors from the top. While the primary detector and preamplifier unit remain in the standard detector box, a short cable is used for operating the secondary detector outside of its box, which houses the preamplifier unit only. The secondary detector is mounted on a support structure, which in turn is solidly fixed to the primary detector box.

The alignment of the secondary field stop is performed by using an artificial external light source. The solar tracker is used for conveniently centring the image of the source on the primary field stop; the evaluation is performed with the camera of the solar tracker. The fine adjustment of the source image on the secondary field stop is performed by aligning the plane mirror; the evaluation is performed by eye with a mag- 


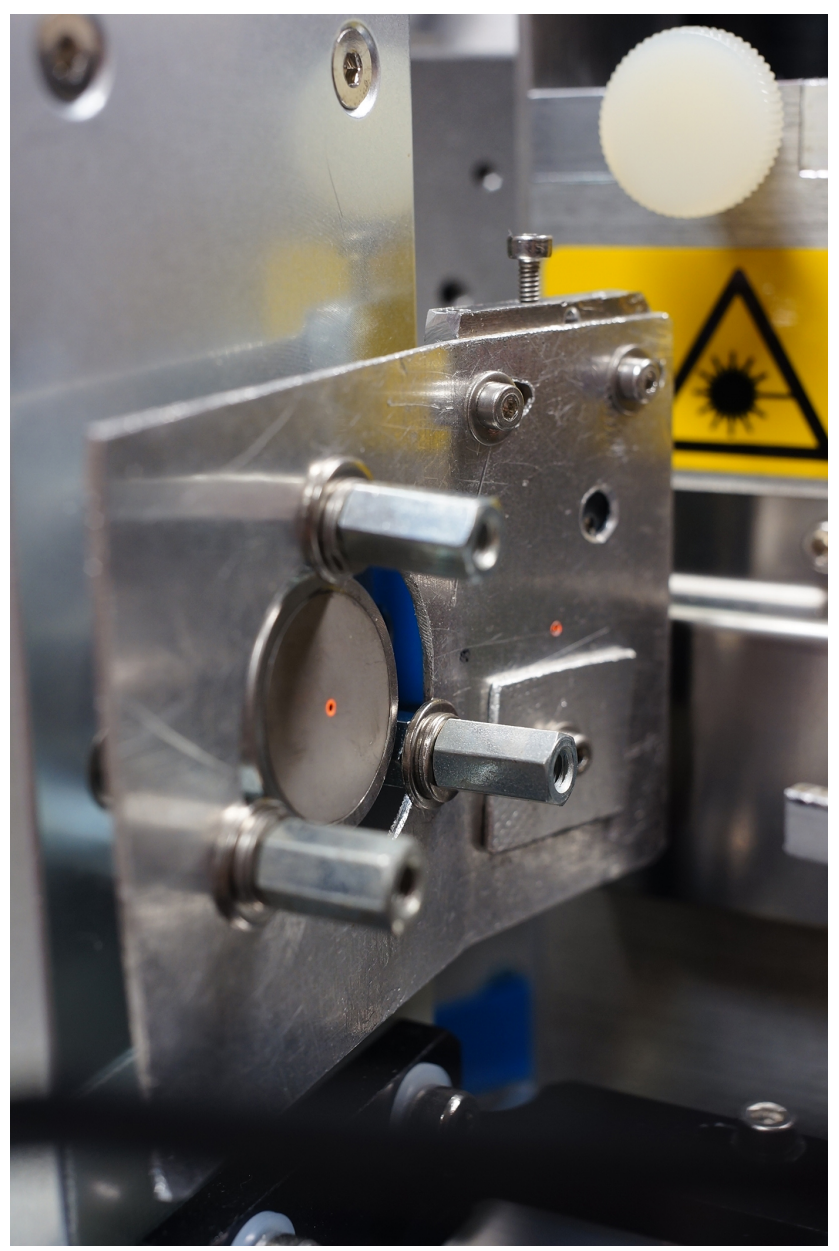

Figure 3. In the front, the image of an artificial source covering about the same angle as the solar disc is seen on the primary field stop. The support for the secondary field stop is mounted on the primary detector. The secondary field stop itself is realised as a $0.8 \mathrm{~mm}$ hole in the aluminium sheet. The image of the source on the secondary field stop is seen to the upper right from the centre of the image. The final alignment of the image position with respect to the position of the secondary field stop is performed by fine adjustment of the plane mirror.

nifier. Finally, the position of the unit containing the wedged Germanium filter and the secondary detector element is adjusted with respect to the secondary field stop by searching for maximum signal level.

\section{Characteristics of spectra recorded with the dual-channel prototype}

Figure 5 (upper panel) shows a lamp spectrum recorded with the prototype. Both the primary and secondary channels are essentially free from channelling (we estimate the upper limit for the peak-to-peak amplitude in the primary channel to be 0.0005 , in the secondary channel to be 0.0002 ), and the desired separated spectral bandpass for each chan-

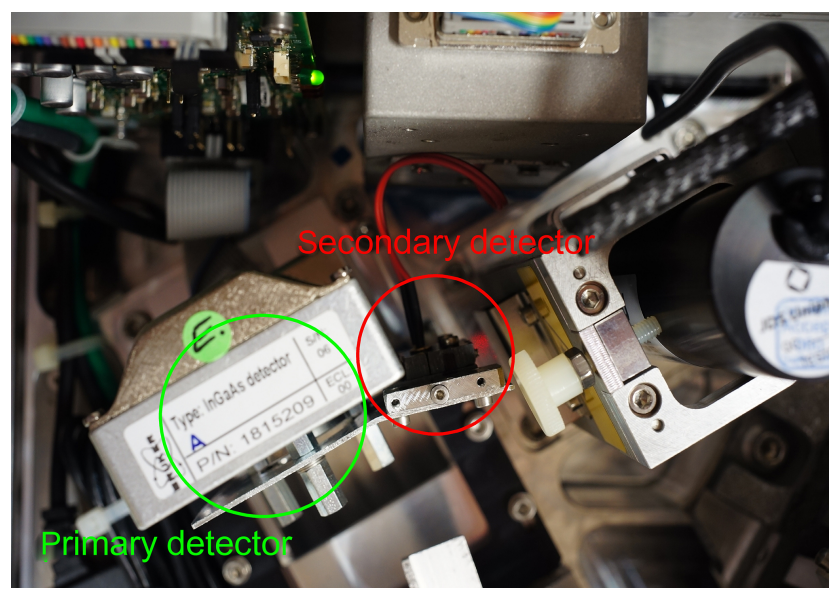

Figure 4. This image provides a top view of the detector units. The primary detector remains in its standard detector box; the supporting structure for the secondary field stop is mounted on the box of the primary detector. The secondary detector and the Ge filter are accommodated in a separate holder, which can be adjusted laterally with respect to the field stop.

nel is achieved: the low-wavenumber limit of the secondary detector results from the cut-off of the diode; its highwavenumber limit is defined by the Ge filter. Similarly, the low-wavenumber limit of the primary detector is shaped by the diode cut-off; the high-wavenumber limit is due to a Schott RG 830 long-pass filter glass that acts as an entrance window of the spectrometer. Therefore, both detectors observe through this optical element, and a further extension of the concept presented here towards lower wavenumbers would in addition to a suited detector element require a replacement of the entrance window (because the glassbased window becomes nontransparent at a wavelength of about $3 \mu \mathrm{m}$ ). Finally, also a beam splitter exchange would be needed, because the standard EM27/SUN is equipped with a Quartz substrate beam splitter.

Figure 5 (lower panel) shows a raw solar spectrum recorded with the prototype. This spectrum reveals that the transition region between both channels coincides nicely with the opaque region created by the strong water vapour absorption between the atmospheric window regions $\mathrm{H}$ and $\mathrm{K}$ (we here refer to the established convention used in infrared astronomy: the $\mathrm{H}$ band covers $1.5-1.8 \mu \mathrm{m}$; the $\mathrm{K}$ band covers 2.0-2.4 $\mu \mathrm{m}$ ). Close inspection of the zero baselines reveals a minor out-of-band offset of the order of $0.015 \%$ for the primary detector branch and no indication of out-of band signal for the secondary detector branch (below $0.0025 \%$ ). The $1 \sigma$ signal-to-noise ratio in the peak of the primary channel is 13000 ; the signal-to-noise ratio of the secondary channel reaches 20000 . 
Table 1. Overview of measurement days before and after modification of the spectrometer. The number of spectra used in the comparison is indicated. The modification of the prototype was performed before 12 October 2015. NIR denotes spectra recorded in the near infrared for the TCCON analysis, MIR denotes mid-infrared observations of the fundamental band of CO as used for the NDACC analysis.

\begin{tabular}{lrrr}
\hline $\begin{array}{l}\text { Date } \\
\text { (JJMMDD) }\end{array}$ & $\begin{array}{r}\text { Number of spectra recorded } \\
\text { with the EM27/SUN selected } \\
\text { for modification (S/N0039) }\end{array}$ & $\begin{array}{r}\text { Number of spectra recorded } \\
\text { with the EM27/SUN used } \\
\text { as a reference (S/N0037) }\end{array}$ & $\begin{array}{r}\text { Number of spectra } \\
\text { recorded with the 125HR } \\
\text { spectrometer (NIR/MIR) }\end{array}$ \\
\hline 150518 & 368 & 369 & n/a \\
150521 & 282 & 276 & n/a \\
150702 & 465 & 477 & n/a \\
150703 & 472 & 473 & n/a \\
150706 & 342 & 344 & n/a \\
150710 & 338 & 330 & n/a \\
150831 & 387 & 400 & $86 / 4$ \\
\hline Modification performed & & & $40 / 3$ \\
\hline 151012 & 206 & Not operated & $72 / 4$ \\
151026 & 186 & 201 & $33 / 2$ \\
151105 & 136 & 173 & $20 / 2$ \\
151110 & 83 & 114 & $71 / 3$ \\
151111 & 103 & 107 & $124 / 7$ \\
151116 & 79 & 63 & 297 \\
160318 & 322 & & \\
\hline
\end{tabular}
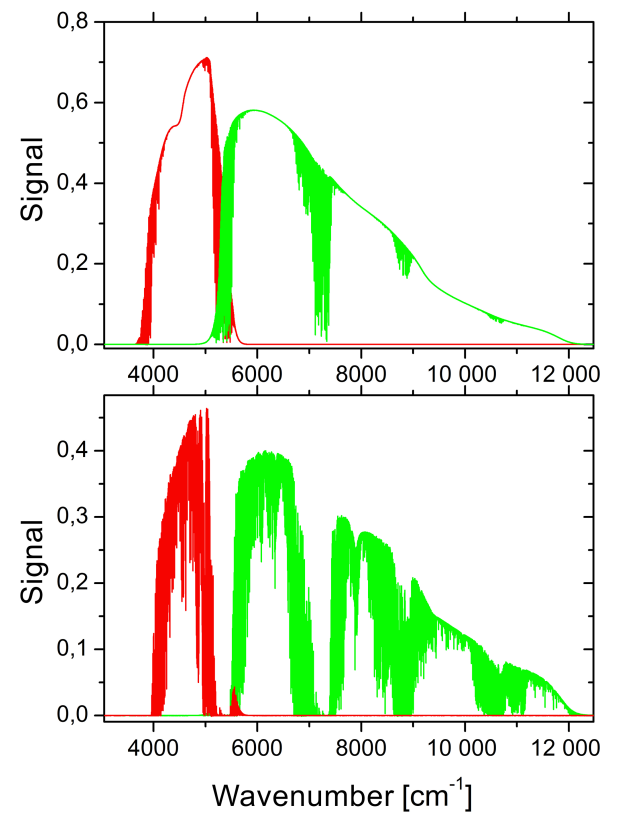

Figure 5. Lamp spectrum (top) and solar spectrum (bottom) recorded with the dual-channel prototype. The primary detector covers the spectral section observed with the standard EM27/SUN; the secondary detector covers the $4000-5500 \mathrm{~cm}^{-1}$ region.

\section{Results of atmospheric retrievals}

To evaluate the instrument performance, the modified spectrometer was operated in parallel to a standard EM27/SUN for 6 days of measurements from mid-October to midNovember 2015 and on 18 March 2016. Before the implementation of the extension, the selected spectrometer was operated side by side with the same standard EM27/SUN on various occasions. This allows us to check whether the modification of the spectrometer changed the oxygen column derived from the primary channel. We assume that the oxygen column is the most sensitive indicator for changes of the instrumental characteristics (especially instrumental line shape, ILS), as instrumental error sources tend to cancel out in the final column-averaged abundances of the target gases. For this purpose, we selected 7 days of measurements before the intervention was performed on the spectrometer and 6 days after the intervention. Table 1 lists the measurements used in this study. The upper part of Table 1 lists the measurements taken between mid-May and the end of August side by side with the spectrometer used for the prototype (before modification) and a standard EM27/SUN used as a reference. The lower part of Table 1 summarises the measurements taken after implementation of the dual-channel extension, the measurements taken with the standard EM27/SUN reference (the same spectrometer as used previously), and the near- and mid-infrared measurements taken with the highresolution FTIR spectrometer at Karlsruhe operated as part of the TCCON. The low-resolution interferograms used in this study passed the quality check implemented in our calibration routines (based on average DC level and DC variations 


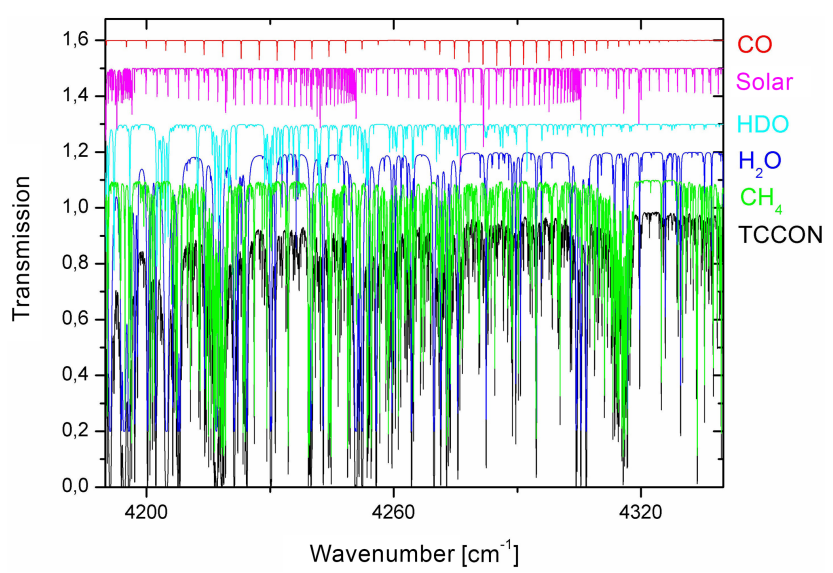

Figure 6. Spectrum simulated for TCCON resolution showing the relevant absorption features in the spectral region under consideration.

during recording), the TCCON data used passed the standard quality flagging of the GGG software suite. For limiting air-mass-dependent effects, data recorded at solar elevations below $15^{\circ}$ have been discarded. Note that the TCCON time series is somewhat sparser than for a typical TCCON site, due to alternating recording of high-resolution mid-infrared spectra.

The EM27/SUN side-by-side observations were performed on the roof terrace of our institute, at a distance of less than $1 \mathrm{~km}$ from the TCCON spectrometer site Karlsruhe. In addition, the TCCON spectrometer was operational during all days of observations with the dual-channel EM27/SUN. Therefore, the official TCCON XCO product derived from these observations can serve as the best available reference for the true column-averaged $\mathrm{CO}$ abundances. In addition to the standard operation mode, the high-resolution spectrometer intermittently records double-sided interferograms with the same resolution as applied by the EM27/SUN, which can be used to evaluate systematic retrieval biases introduced by the significantly different resolution of the TCCON spectrometer and the EM27/SUN.

For the pre-processing of the EM27/SUN raw data, our suite of CALPY routines was used (Frey et al., 2015). For the analysis of the EM27/SUN we applied the retrieval code PROFFIT (Hase et al., 2004). PROFFIT is in wide use in the NDACC (e.g. Sepúlveda et al., 2014; Virolainen et al., 2014; Mengistu Tsidu et al., 2015), is in very good agreement with the official TCCON analysis (Dohe, 2013), and is also successfully applied for the analysis of spectra recorded with the EM27/SUN (Gisi et al., 2012; Frey et al., 2015). For the analysis of the low-resolution spectra, the methane, water vapour, $\mathrm{HDO}$, and $\mathrm{CO}$ a priori profiles were adopted from the TCCON processor. Figure 6 shows the complex spectral region containing the $\mathrm{CO}$ overtone band as recorded at high spectral resolution and denotes the absorption contributions from the relevant absorbers. Figure 7 shows a typical spectral fit for

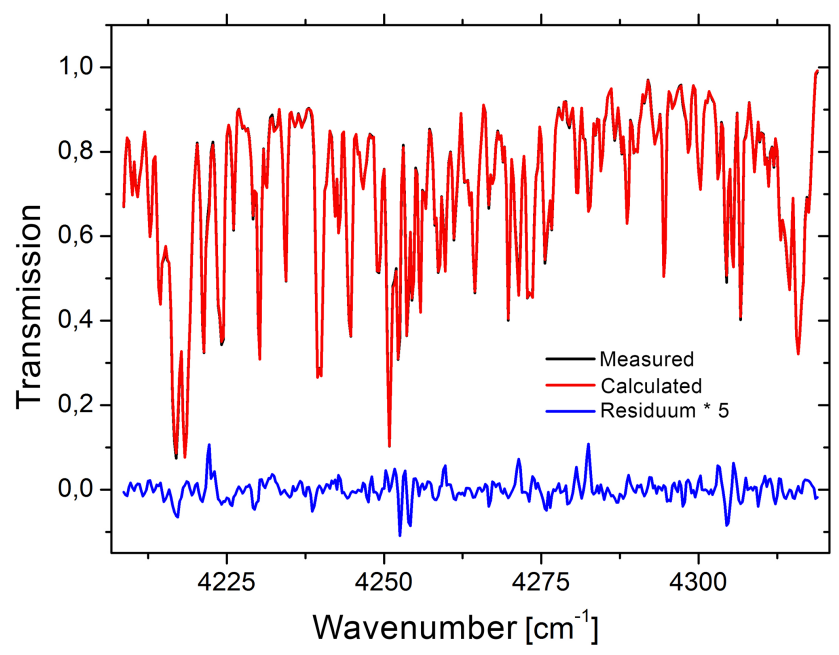

Figure 7. Typical spectral fit for the selected $\mathrm{CO}$ fitting region $\left(4210-4320 \mathrm{~cm}^{-1}\right)$. Interfering species are $\mathrm{CH}_{4}, \mathrm{H}_{2} \mathrm{O}$, and HDO.

the spectral window $4210-4320 \mathrm{~cm}^{-1}$, which is used for the $\mathrm{CO}$ analysis. Systematic fit residuals significantly larger than the noise level of the spectrometer are evident, indicating that the simulation of this crowded spectral scene shaped by numerous strong absorption lines could be improved by further progress on spectroscopic data (our fits are essentially based on HITRAN 2008; see Rothman et al., 2008). The provision of an improved and consolidated set of spectroscopic data for the spectral region under consideration here is an ongoing effort (e.g. Galli et al., 2012; Scheepmaker et al., 2013; http://seom.esa.int/page_project003.php).

Before we discuss results derived from the new spectral channel, we investigate whether the modifications performed on the prototype affected the results for the oxygen column, which is derived from the existing spectral channel. Figure 8 compares the oxygen column from the dual-channel prototype before and after the intervention and the standard EM27/SUN used as a reference. The agreement meets our design expectations; no detectable offset as result of the dualchannel implementation is found. We therefore assume that the implementation of the extension did not significantly affect the behaviour of spectrometer's primary channel. Note that a comparison of oxygen columns is a very sensitive test, as many instrumental errors tend to cancel out in the final column averaged abundances of the target species.

Next, we investigate the compatibility of $\mathrm{CH}_{4}$ columns derived from the primary detector with the $\mathrm{CH}_{4}$ columns from the secondary detector. $\mathrm{CH}_{4}$ is the main absorber in the $4200-4320 \mathrm{~cm}^{-1}$ region, followed by $\mathrm{H}_{2} \mathrm{O}$ and $\mathrm{HDO}$. The $\mathrm{CO}$ overtone band is weak in comparison to the signatures of the other species, so $\mathrm{CH}_{4}$ provides a more sensitive handle for revealing any instrumental issues. Figure 9 shows the $\mathrm{CH}_{4}$ columns from both channels of the prototype. The two data sets are in mutual agreement on the $0.1 \%$ level. There 

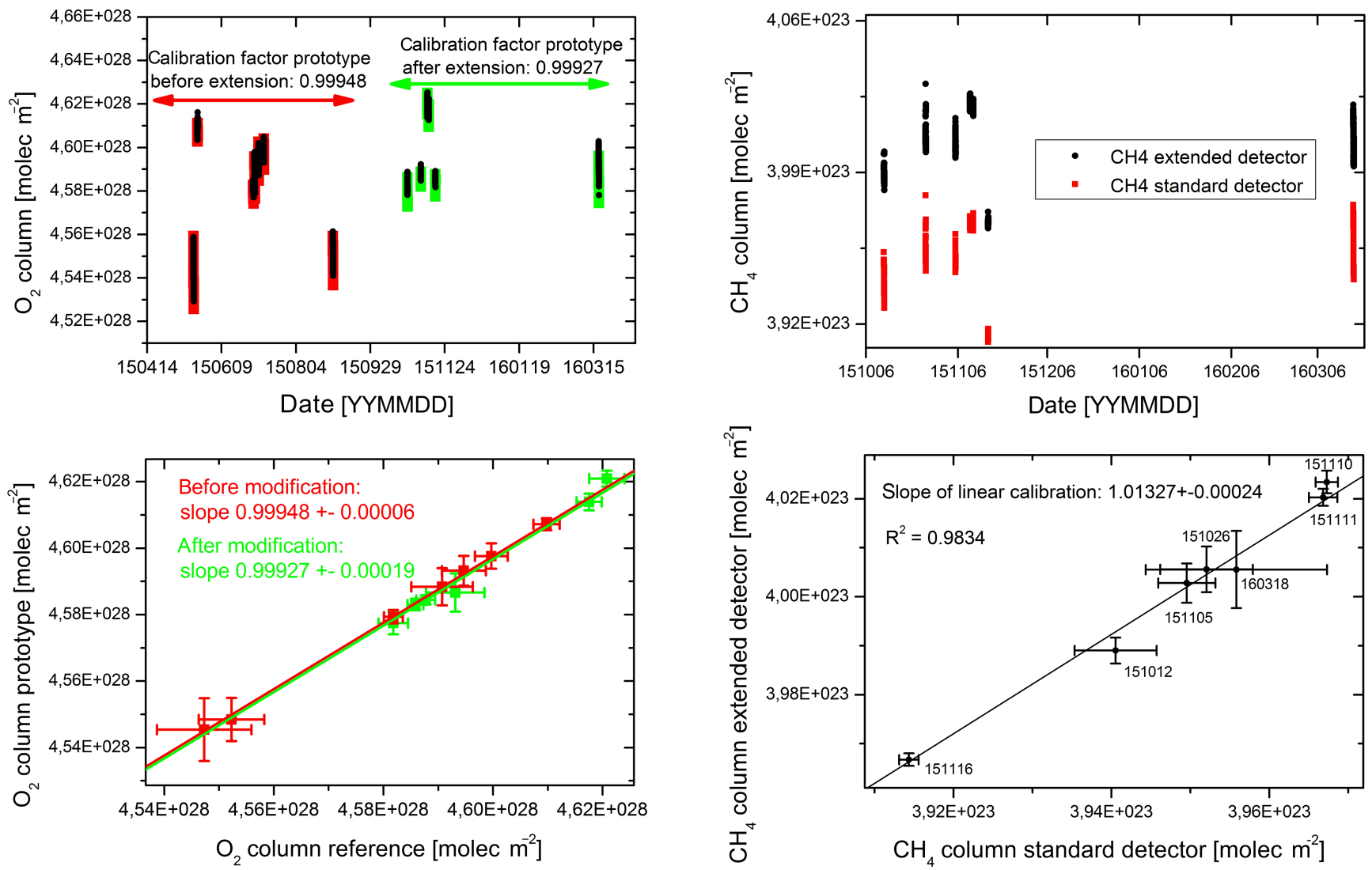

Figure 8. Total column amounts of molecular oxygen measured with the EM27/SUN used as a reference (data in black) and the prototype before and after the implementation (before: red; after: green) of the secondary channel. The implemented extension did not affect the characteristics of the prototype. Upper panel: time series of the $\mathrm{O}_{2}$ column amounts as recorded with the reference spectrometer and the prototype. Lower panel: Mean daily $\mathrm{O}_{2}$ column amounts as recorded with the prototype as a function of the values recorded with the reference spectrometer. The error bars shown are the standard deviation of the intraday scatter. The calibration factors before and after the modification of the prototype are in mutual agreement.

is a systematic offset between the two time series (scaling factor $1.0133 \pm 0.0024$ ), very likely due to residual inconsistencies of the spectroscopic line intensities. The standard deviation of the ratio of both time series is $0.104 \%$. It should be noted that a misalignment between the primary and secondary field stop would induce systematic differences as a function of azimuthal viewing angle. Indeed, the comparison of the two methane products provides a tool for detecting a misalignment of the secondary field stop, because a variation induced by our limited capability to simulate the spectral scene will be symmetric around local noon, whereas the field stop misalignment will differ between morning and afternoon as a consequence of the rotation of the image on the field stop as a function of azimuthal viewing angle (Reichert

Figure 9. Comparison of methane column amounts as derived from the primary and secondary spectral channel. Upper panel: time series of methane columns. Lower panel: daily mean values of methane columns derived from the extended detector as a function of the methane columns derived from the standard detector. The error bars are the standard deviations of the intraday scatter. A linear fit of the calibration factor suggests a systematic spectroscopic offset of 1.013. There is no indication of a drift of the instrumental characteristics of the extended detector results with respect to the standard detector.

et al., 2015). At a solar elevation angle of $20^{\circ}$ a $0.1^{\circ}$ displacement of the solar disc would create an error of up to $0.5 \%$ in dry-air mole fractions derived from the secondary channel (solar elevation $10^{\circ}$ : up to $1 \%$ ), so this effect can easily be detected using the two methane data products and subsequently be applied for establishing a correction for XCO if required. However, we do not observe such a suspicious discrepancy between the two time series.

Finally, we investigate the XCO time series derived from the prototype. Figure 10 displays measurements recorded in the $15-33^{\circ}$ range of solar elevation angles; the daily mean values have been scaled in order to remove the day-to-day variability. Obviously, the results are affected by an air mass dependency. The presence of such an artificial air mass dependency is a frequent problem created by our inability to simulate the observed spectral scene perfectly. We therefore 


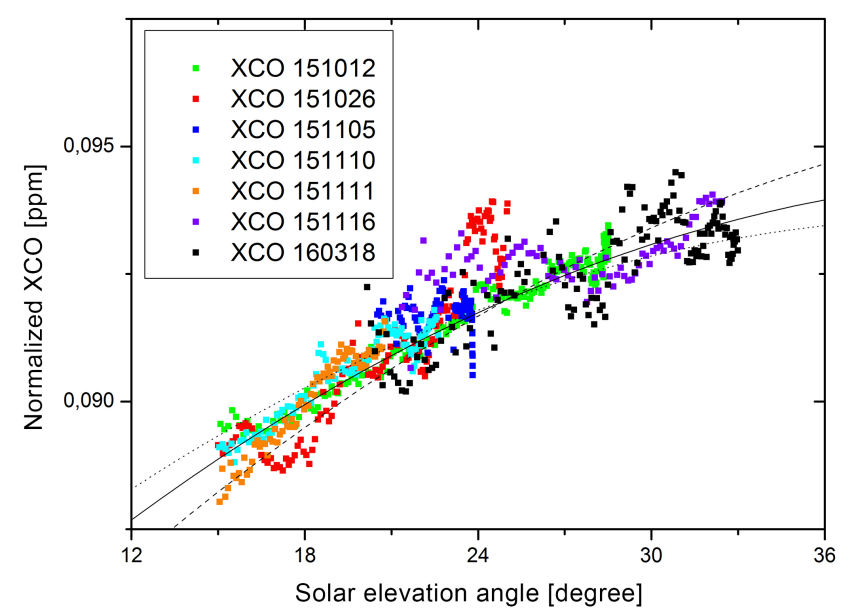

Figure 10. Apparent air mass dependency of the XCO data observed with the dual-channel prototype. For the air mass correction, we applied a second-order polynomial fit, choosing $25^{\circ}$ as the neutral point. For establishing the correction, spectra taken between 15 and $33^{\circ}$ SEA have been taken into account. This choice results in the functional form $\left(1+0.0027 \times\left(\mathrm{SEA}-25^{\circ}\right)-0.00007 \times(\mathrm{SEA}-\right.$ $\left.25^{\circ}\right)^{2}$ ), wherein SEA denotes the solar elevation angle (solid curve). For estimating the uncertainty introduced by the air mass correction when comparing the prototype XCO results with the TCCON, the linear term of the fit has been increased to 0.0034 (overcorrection, dashed curve) and decreased to 0.0022 (undercorrection, dotted curve).

apply a second-order polynomial (shown in Fig. 10) to remove this artefact. We have located the neutral point of this correction at $25^{\circ}$ solar elevation angle, which is near the average solar elevation angle of the complete data set. Figure 10 in addition shows a strong and a weak variant of the correction, which result in significantly poorer fits to the observed data. These two ad hoc modifications will be used in the comparison with the TCCON reference data set for estimating the level of uncertainty introduced by the air mass correction. The TCCON also requires the aid of empirical air mass corrections for carbon monoxide and other target species.

Figure 11 presents the XCO data as derived from the dualchannel EM27/SUN prototype in comparison to the official TCCON data product. The air mass correction clearly improves the agreement with the TCCON reference (as seen in the upper panel of Fig. 11). The XCO results deduced from the dual-channel prototype are in agreement with the TCCON reference data set (within the statistical uncertainty of the calibration factor). The strong and weak variants of the air mass correction do somewhat affect the calibration factor of the prototype XCO. However, the resulting deviations from unity are still not significant on the $2 \sigma$ level of the statistical uncertainty. Note that apart from the empirical air mass correction and the TCCON calibration factor derived from aircraft measurements (Kiel et al., 2016b) no adjustments on the $\mathrm{XCO}$ derived from the prototype have been applied. The pre-
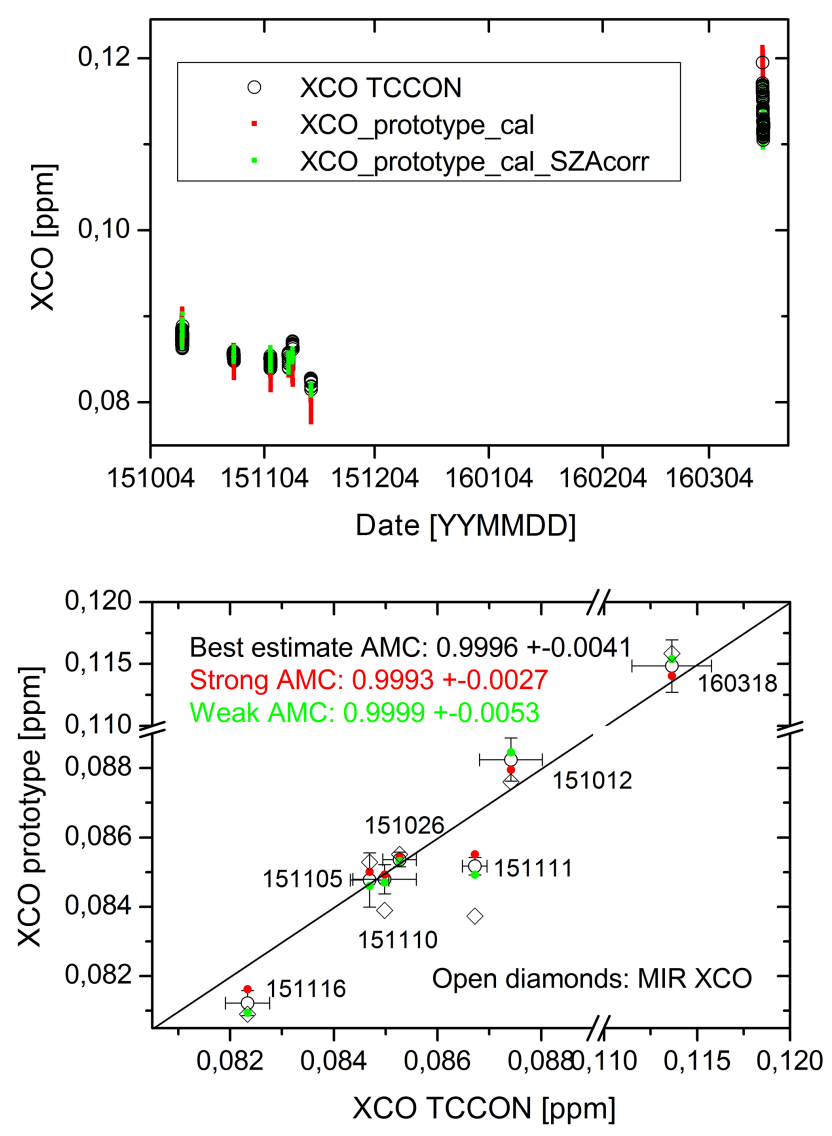

Figure 11. XCO deduced from the dual-channel prototype and the TCCON site Karlsruhe. Upper panel: time series of XCO. Lower panel: $\mathrm{XCO}$ values measured with the prototype as a function of the collocated TCCON XCO values (AMC denotes air mass correction). The error bars are the standard deviations of the intraday scatter. In the upper panel, all available TCCON values have been taken into account, whereas for the calculation of the statistics shown in the lower panel the TCCON measurements have been restricted to the observing hours of the prototype, because the intraday variability is not negligible in the case of XCO. As indicated by the calibration factors, the choice of the air mass correction does not critically impact the level of agreement found between the prototype and the TCCON XCO observations. The lower panel of the figure in addition shows XCO results derived from high-resolution midinfrared spectra (open diamonds), analysed as described by Kiel et al. (2016b) (the calibration factor of 0.954 recommended by Kiel et al. has been applied to the mid-infrared data to match with the calibration of the TCCON).

cision of an individual XCO measurement can be estimated from differences of successive measurements and amounts to $0.35 \mathrm{ppb}$.

The vertical sensitivity of the low-resolution spectrometer differs somewhat from the TCCON sensitivity. This is a consequence of differing spectral resolutions and introduces a smoothing error component in the comparison. Sensitivities for both the low-resolution spectrometer and TCCON 


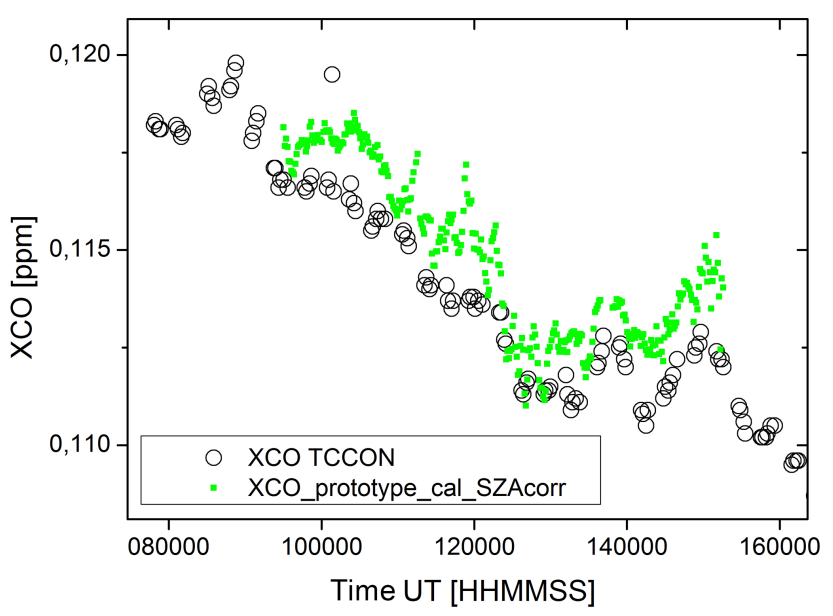

Figure 12. XCO intraday variability as observed during 18 March 2016, by the TCCON spectrometer and the dual-channel prototype.

are shown in the work by Hedelius et al. (2016), indicating that the CO sensitivity of the low-resolution spectrometer is even superior to that of the TCCON. In this study - focused on an instrumental validation - we minimised the systematic smoothing error contribution by using the same atmospheric $\mathrm{CO}$ a priori profiles as the TCCON in our spectral analysis. An in-depth quantification of the smoothing error has been performed by Kiel et al. (2016b). The authors compared TCCON results with data derived from mid-infrared spectra (with a comparable degree of mismatch of vertical sensitivities) and found smoothing error contributions of a few per cent due to different a priori profile choices and vertical sensitivities. We have included the mid-infrared observations of XCO in the lower panel of Fig. 11, because these results support our explanation of the remaining discrepancies being generated by different vertical sensitivities of the TCCON and the prototype measurements: the mid-infrared observations of XCO tend to be low compared to the TC$\mathrm{CON}$ when the prototype results are low and high when the prototype results are high.

The demonstrated performance of the prototype indicates that the design is well suited for source attribution (Wunch et al., 2009; detected intraday XCO enhancements of up to $30 \%$ in the Los Angeles Basin) and satellite validation (the TROPOMI accuracy and precision targets are 15 and $10 \%$, respectively). We expect that the upcoming set of improved spectroscopic data will further improve the reliability of XCO derived from low-resolution spectra (ideally rendering the air-mass-dependent correction obsolete).

On 18 March 2016, a larger intraday variability of XCO occurred, which has been nicely sampled by both the TCCON spectrometer and the prototype. The results are shown in Fig. 12, indicating that the prototype can detect XCO intraday variability in the sub-per-cent range.

\section{Summary and outlook}

The portable EM27/SUN spectrometer is dedicated to measurements of column-averaged abundances of carbon dioxide and methane with sufficient quality for climate research. In this work, we have described a dual-channel extension of this device, which can be added in a straightforward manner without interfering with the standard set-up of the spectrometer. The second channel uses an extended InGaAs detector element and a wedged Ge filter to define a spectral bandpass beyond the spectral coverage of the standard spectrometer. It is fed via a small plane mirror which decouples parts of the beam towards a secondary detector element. This approach avoids interference with the concept of a camera-controlled tracker referenced to the field stop and conserves the spectral coverage and characteristics of the primary detector. The secondary detector allows the simultaneous measurement of $\mathrm{XCO}$, which is a very useful tool for source characterisation, while the use of a cooled detector element can be avoided. In the second part of this work, we performed a preliminary validation of the set-up by verifying that the dual-channel prototype maintains the characteristics of the standard spectrometer and by investigating the XCO data product. We showed that, due to the fact that methane is the primary absorber in the spectral window used for the carbon monoxide analysis, the comparison of $\mathrm{CH}_{4}$ columns derived from either the primary or the secondary channel can be used as a diagnostic tool for detecting a residual misalignment of the secondary field stop or other instrumental issues.

We plan a further in-depth characterisation of the dualchannel EM27/SUN prototype introduced here. The spectrometer is foreseen to participate in the TCCONcomp campaign funded by ESA. This campaign is scheduled for 2017; is led by University of Bremen, Germany, and BIRA (Royal Belgian Institute for Space Aeronomy), Belgium; and involves several partners contributing various promising approaches for the Sentinel 5 Precursor validation. The aim of TCCONcomp is to validate these techniques with respect to the TCCON reference instrument operated by FMI (Finnish Meteorological Institute) at the Sodankyla station, Finland.

We would like to mention that the secondary channel of the extended EM27/SUN also allows observation of HDO, opening up the possibility of also using the device for observations of water vapour isotopic variability, although the verification of the quality and information content of such data from low-resolution spectra will require careful validation efforts (for prior work based on high-resolution nearinfrared spectra see Rokotyan et al., 2014). The new spectroscopic data sets under preparation in support of the Sentinel 5 Precursor mission will be a highly valuable ingredient for the TCCON; the spectrometer presented here; and any other remote sensing devices working in the $2.35 \mu \mathrm{m}$ spectral region targeting methane, carbon monoxide, or water vapour isotopic composition. 
Acknowledgements. We acknowledge support by the ACROSS and MOSES research infrastructure of the Helmholtz Association.

We acknowledge support by the Deutsche Forschungsgemeinschaft and Open Access Publishing Fund of the Karlsruhe Institute of Technology.

We thank the anonymous referees for triggering numerous useful corrections of the original manuscript.

The article processing charges for this open-access publication were covered by a Research

Centre of the Helmholtz Association.

Edited by: J. Notholt

\section{References}

Butz, A., Guerlet, S., Jacob, D. J., Schepers, D., Galli, A., Aben, I., Frankenberg, C., Hartmann, J.-M., Tran, H., Kuze, A., KeppelAleks, G., Toon, G. C., Wunch, D., Wennberg, P. O., Deutscher, N. M., Griffith, D. W. T., Macatangay, R., Messerschmidt, J., Notholt, J., and Warneke, T.: Toward accurate $\mathrm{CO}_{2}$ and $\mathrm{CH}_{4}$ observations from GOSAT, Geophys. Res. Lett., 38, 2-7, doi:10.1029/2011GL047888, 2011.

Dohe, S.: Measurements of atmospheric $\mathrm{CO}_{2}$ columns using ground-based FTIR spectra, Dissertation, Karlsruhe Institute for Technolgy (KIT), Germany, 2013.

Frey, M., Hase, F., Blumenstock, T., Groß, J., Kiel, M., Mengistu Tsidu, G., Schäfer, K., Sha, M. K., and Orphal, J.: Calibration and instrumental line shape characterization of a set of portable FTIR spectrometers for detecting greenhouse gas emissions, Atmos. Meas. Tech., 8, 3047-3057, doi:10.5194/amt-8-3047-2015, 2015.

Galli, A., Butz, A., Scheepmaker, R. A., Hasekamp, O., Landgraf, J., Tol, P., Wunch, D., Deutscher, N. M., Toon, G. C., Wennberg, P. O., Griffith, D. W. T., and Aben, I.: $\mathrm{CH}_{4}$, CO, and $\mathrm{H}_{2} \mathrm{O}$ spectroscopy for the Sentinel-5 Precursor mission: an assessment with the Total Carbon Column Observing Network measurements, Atmos. Meas. Tech., 5, 1387-1398, doi:10.5194/amt-51387-2012, 2012.

Gisi, M., Hase, F., Dohe, S., and Blumenstock, T.: Camtracker: a new camera controlled high precision solar tracker system for FTIR-spectrometers, Atmos. Meas. Tech., 4, 47-54, doi:10.5194/amt-4-47-2011, 2011.

Gisi, M., Hase, F., Dohe, S., Blumenstock, T., Simon, A., and Keens, A.: XCO-2-measurements with a tabletop FTS using solar absorption spectroscopy, Atmos. Meas. Tech., 5, 2969-2980, doi:10.5194/amt-5-2969-2012, 2012.

Hase, F., Hannigan, J., Coffey, M., Goldman, A., Höpfner, M., Jones, N., Rinsland, C., and Wood, S.: Intercomparison of retrieval codes used for the analysis of high resolution, groundbased FTIR measurements, J. Quant. Spectrosc. Ra., 87, 25-52, doi:10.1016/j.jqsrt.2003.12.008, 2004.

Hase, F., Frey, M., Blumenstock, T., Groß, J., Kiel, M., Kohlhepp, R., Mengistu Tsidu, G., Schäfer, K., Sha, M. K., and Orphal, J.: Application of portable FTIR spectrometers for detecting greenhouse gas emissions of the major city Berlin, Atmos. Meas. Tech., 8, 3059-3068, doi:10.5194/amt-8-3059-2015, 2015.
Hedelius, J. K., Viatte, C., Wunch, D., Roehl, C., Toon, G. C., Chen, J., Jones, T., Wofsy, S. C., Franklin, J. E., Parker, H., Dubey, M. K., and Wennberg, P. O.: Assessment of errors and biases in retrievals of $\mathrm{XCO}_{2}, \mathrm{XCH}_{4}, \mathrm{XCO}$, and $\mathrm{XN}_{2} \mathrm{O}$ from a $0.5 \mathrm{~cm}^{-1}$ resolution solar viewing spectrometer, Atmos. Meas. Tech. Discuss., doi:10.5194/amt-2016-39, in review, 2016.

Heymann, J., Reuter, M., Hilker, M., Buchwitz, M., Schneising, O., Bovensmann, H., Burrows, J. P., Kuze, A., Suto, H., Deutscher, N. M., Dubey, M. K., Griffith, D. W. T., Hase, F., Kawakami, S., Kivi, R., Morino, I., Petri, C., Roehl, C., Schneider, M., Sherlock, V., Sussmann, R., Velazco, V. A., Warneke, T., and Wunch, D.: Consistent satellite $\mathrm{XCO}_{2}$ retrievals from SCIAMACHY and GOSAT using the BESD algorithm, Atmos. Meas. Tech., 8, 2961-2980, doi:10.5194/amt-8-2961-2015, 2015.

Inoue, M., Morino, I., Uchino, O., Nakatsuru, T., Yoshida, Y., Yokota, T., Wunch, D., Wennberg, P. O., Roehl, C. M., Griffith, D. W. T., Velazco, V. A., Deutscher, N. M., Warneke, T., Notholt, J., Robinson, J., Sherlock, V., Hase, F., Blumenstock, T., Rettinger, M., Sussmann, R., Kyrö, E., Kivi, R., Shiomi, K., Kawakami, S., De Mazière, M., Arnold, S. G., Feist, D. G., Barrow, E. A., Barney, J., Dubey, M., Schneider, M., Iraci, L., Podolske, J. R., Hillyard, P., Machida, T., Sawa, Y., Tsuboi, K., Matsueda, H., Sweeney, C., Tans, P. P., Andrews, A. E., Biraud, S. C., Fukuyama, Y., Pittman, J. V., Kort, E. A., and Tanaka, T.: Bias corrections of GOSAT SWIR $\mathrm{XCO}_{2}$ and $\mathrm{XCH}_{4}$ with TC$\mathrm{CON}$ data and their evaluation using aircraft measurement data, Atmos. Meas. Tech. Discuss., doi:10.5194/amt-2015-366, in review, 2016.

Keppel-Aleks, G., Toon, G. C., Wennberg, P. O., and Deutscher, N. M.: Reducing the impact of source brightness fluctuations on spectra obtained by Fourier-transform spectrometry, Appl. Optics, 46, 4774-4779, 2007.

Kiel, M., Wunch, D., Wennberg, P. O., Toon, G. C., Hase, F., and Blumenstock, T.: Improved retrieval of gas abundances from near-infrared solar FTIR spectra measured at the Karlsruhe TCCON station, Atmos. Meas. Tech., 9, 669-682, doi:10.5194/amt9-669-2016, 2016a.

Kiel, M., Hase, F., Blumenstock, T., and Kirner, O.: Comparison of XCO abundances from the Total Carbon Column Observing Network and the Network for the Detection of Atmospheric Composition Change measured in Karlsruhe, Atmos. Meas. Tech. Discuss., doi:10.5194/amt-2015-364, in review, 2016b.

Klappenbach, F., Bertleff, M., Kostinek, J., Hase, F., Blumenstock, T., Agusti-Panareda, A., Razinger, M., and Butz, A.: Accurate mobile remote sensing of $\mathrm{XCO}_{2}$ and $\mathrm{XCH}_{4}$ latitudinal transects from aboard a research vessel, Atmos. Meas. Tech., 8, 50235038, doi:10.5194/amt-8-5023-2015, 2015.

Lindenmaier, R., Dubey, M. K., Henderson, B. G., Butterfield, Z. T., Herman, J. R., Rahn, T., and Lee, S.: Multiscale observations of $\mathrm{CO}_{2},{ }^{13} \mathrm{CO}_{2}$, and pollutants at Four Corners for emission verification and attribution, P. Natl. Acad. Sci. USA, 111, 8386-8391, doi:10.1073/pnas.1321883111, 2014.

Mengistu Tsidu, G., Blumenstock, T., and Hase, F.: Observations of precipitable water vapour over complex topography of Ethiopia from ground-based GPS, FTIR, radiosonde and ERA-Interim reanalysis, Atmos. Meas. Tech., 8, 3277-3295, doi:10.5194/amt-83277-2015, 2015.

Messerschmidt, J., Parazoo, N., Wunch, D., Deutscher, N. M., Roehl, C., Warneke, T., and Wennberg, P. O.: Evaluation of 
seasonal atmosphere-biosphere exchange estimations with TCCON measurements, Atmos. Chem. Phys., 13, 5103-5115, doi:10.5194/acp-13-5103-2013, 2013.

Petri, C., Warneke, T., Jones, N., Ridder, T., Messerschmidt, J., Weinzierl, T., Geibel, M., and Notholt, J.: Remote sensing of $\mathrm{CO}_{2}$ and $\mathrm{CH}_{4}$ using solar absorption spectrometry with a low resolution spectrometer, Atmos. Meas. Tech., 5, 1627-1635, doi:10.5194/amt-5-1627-2012, 2012.

Reichert, A., Hausmann, P., and Sussmann, R.: Pointing errors in solar absorption spectrometry - correction scheme and its validation, Atmos. Meas. Tech., 8, 3715-3728, doi:10.5194/amt-83715-2015, 2015.

Reuter, M., Bovensmann, H., Buchwitz, M., Burrows, J. P., Connor, B. J., Deutscher, N. M., Griffith, D. W. T., Heymann, J., KeppelAleks, G., Messerschmidt, J., Notholt, J., Petri, C., Robinson, J., Schneising, O., Sherlock, V., Velazco, V., Warneke, T., Wennberg, P. O., and Wunch, D.: Retrieval of atmospheric $\mathrm{CO}_{2}$ with enhanced accuracy and precision from SCIAMACHY: Validation with FTS measurements and comparison with model results, J. Geophys. Res., 116, 1-13, doi:10.1029/2010JD015047, 2011.

Rokotyan, N. V., Zakharov, V. I., Gribanov, K. G., Schneider, M., Bréon, F.-M., Jouzel, J., Imasu, R., Werner, M., Butzin, M., Petri, C., Warneke, T., and Notholt, J.: A posteriori calculation of $\delta^{18} \mathrm{O}$ and $\delta \mathrm{D}$ in atmospheric water vapour from ground-based near-infrared FTIR retrievals of $\mathrm{H}_{2}^{16} \mathrm{O}, \mathrm{H}_{2}^{18} \mathrm{O}$, and $\mathrm{HD}^{16} \mathrm{O}$, Atmos. Meas. Tech., 7, 2567-2580, doi:10.5194/amt-7-2567-2014, 2014.

Rothman, L. S., Gordon, I. E., Barbe, A., Benner, D. C., Bernath, P. F., Birk, M., Boudon, V., Brown, L. R., Campargue, A., Champion, J.-P., Chance, K., Coudert, L. H., Dana, V., Devi, V. M., Fally, S., Flaud, J.-M., Gamache, R. R., Goldman, A., Jacquemart, D., Kleiner, I., Lacome, N., Lafferty, W. J., Mandin, J.-Y., Massie, S. T., Mikhailenko, S. N., Miller, C. E., Moazzen-Ahmadi, N., Naumenko, O. V., Nikitin, A. V., Orphal, J., Perevalov, V. I., Perrin, A., Predoi-Cross, A., Rinsland, C. P., Rotger, M., Simeckova, M., Smith, M. A. H., Sung, K., Tashkun, S. A., Tennyson, J., Toth, R. A., Vandaele, A. C., and Vander Auwera, J.: The HITRAN 2008 molecular spectroscopic database, J. Quant. Spectrosc. Ra., 110, 533-572, doi:10.1016/j.jqsrt.2009.02.013, 2009.
Scheepmaker, R. A., Frankenberg, C., Galli, A., Butz, A., Schrijver, H., Deutscher, N. M., Wunch, D., Warneke, T., Fally, S., and Aben, I.: Improved water vapour spectroscopy in the $4174-4300 \mathrm{~cm}^{-1}$ region and its impact on SCIAMACHY $\mathrm{HDO} / \mathrm{H}_{2} \mathrm{O}$ measurements, Atmos. Meas. Tech., 6, 879-894, doi:10.5194/amt-6-879-2013, 2013.

Sepúlveda, E., Schneider, M., Hase, F., Barthlott, S., Dubravica, D., García, O. E., Gomez-Pelaez, A., González, Y., Guerra, J. C., Gisi, M., Kohlhepp, R., Dohe, S., Blumenstock, T., Strong, K., Weaver, D., Palm, M., Sadeghi, A., Deutscher, N. M., Warneke, T., Notholt, J., Jones, N., Griffith, D. W. T., Smale, D., Brailsford, G. W., Robinson, J., Meinhardt, F., Steinbacher, M., Aalto, T., and Worthy, D.: Tropospheric $\mathrm{CH}_{4}$ signals as observed by NDACC FTIR at globally distributed sites and comparison to GAW surface in situ measurements, Atmos. Meas. Tech., 7, 2337-2360, doi:10.5194/amt-7-2337-2014, 2014.

Virolainen, Y., Timofeyev, Y., Polyakov, A., Ionov, D., and Poberovsky, A: Intercomparison of satellite and ground-based measurements of ozone, $\mathrm{NO}_{2}, \mathrm{HF}$, and $\mathrm{HCl}$ near Saint Petersburg, Russia, Int. J. Remote Sens., 35, 5677-5697, doi:10.1080/01431161.2014.945009, 2014.

Wunch, D., Wennberg, P. O., Toon, G. C., Keppel-Aleks, G., and Yavin, Y. G.: Emissions of greenhouse gases from a North American megacity, Geophys. Res. Lett., 36, 1-5, doi:10.1029/2009GL039825, 2009.

Wunch, D., Toon, G. C., Blavier, J.-F. L., Washenfelder, R. A., Notholt, J., Connor, B. J., Griffith, D. W. T., Sherlock, V., and Wennberg, P. O.: The Total Carbon Column Observing Network, Phil. Trans. R. Soc. A, 369, 2087-2112, doi:10.1098/rsta.2010.0240, 2011. 